probably not too much that any one of us can do to make ourselves more intelligent, we certainly can learn to reason and research more efficiently and effectively.

\section{Appendix: The Mentor Chain}

Julius Axelrod, 1970 Nobel Prize Winner in Physiology and Medicine, on his mentor, Bernard Brodie, Goldwater Memorial Hospital, New York:

He made every experiment seem earthshattering and encouraged the kind of 'quick and dirty' experiment that might suggest whether an approach was worth pursuing more deliberately. ... Somehow, by taking a chance and driving ahead, it was as if you were wrestling with the gods themselves. Instead of thinking of all the reasons why you should hold off, Brodie's dictum was: 'Oh let's take a flier on it.'

... Do an apparently simple experiment that gives you an important bit of information. . . . Ask the important question at the right time. If you ask it later, then it's obvious.

Solomon H. Snyder, professor of pharmacology at Johns Hopkins Medical Center, on the style he learned from his mentor, Julius Axelrod:

... science is as creative as any of the arts. He'd talk of theories that were beautiful ... symmetrical ... the kind of things you get excited about, lose sleep over.
... A student will say, 'But it's good science, isn't it?' and I'll say, 'Yes, but it's boring. I think we can do something more exciting.

Candace Pert, National Institutes of Health, on her mentor, Solomon H. Snyder:

He had a pragmatic, handyman approach to science. He was always sidestepping the grey muck of experimental tedium, always reaching for the heady scientific heights-the more fundamental, more exciting problems that sneered at routine. He went right after what he wanted: Need a new technique just appearing in the scientific literature? Don't spend days in the library poring over journals; just call up its originator and get the details directly. Spy a striking new tack to take with a problem? Don't worry about scientific controls for now: 'Just get hysterical and do it.'

Terry Moody, assistant professor of biochemistry at the George Washington Medical Center, on his mentor, Candace Pert:

She's always willing to take the longshot.

Source: Developed from Robert Kanigel, "The Mentor Chain." F\&M Today 10:5, 1981, 1-8.

\section{Notes}

1. The first draft of this essay was prepared for members of the 3-I (Illinois, Indiana, Iowa) seminar on complex systems. This is an edited version of a later draft, presented at the meetings of the Midwest Political Science Association in Chicago, Illinois, in April of 1986. It should be noted that Professor Most had planned to make some revisions before submitting this piece for publication, and that $I$ have edited it in spots for that purpose. Therefore responsibility for any errors is mine, and not his.

2. See Platt (1964, pp. 347-353) for a more detailed discussion of what is involved in the method of strong inference.

3. See Most and Starr (1989, chap. 7) for a further discussion of the utility of stylized facts. See Chapter 6 of this book, and Most and Starr (1987) for the results of the research project described here.

\section{References}

Broad, William J. 1985. "Subtle Analogies Found at the Core of Edison's Genius." New York Times, 12 March, sec. C.

Bronowski, Jacob. 1965. Science and Human Values. New York: Harper and Row.

Kanigel, Robert. 1981. "The Mentor Chain." F\&M Today 10:5, pp. 1-8.

Lave, Charles and James G. March. 1975. An Introduction to Models in the Social Sciences. New York: Harper and Row.

Most, Benjamin A. and Harvey Starr. 1987. "Polarity, Preponderance, and Power Parity in the Generation of International Conflict." International Interactions 13: 225-262.

Most, Benjamin A. and Harvey Starr. 1989. Inquiry, Logic and International Politics. Columbia, SC: University of South Carolina Press.

Platt, John R. 1964. "Strong Inference." Science, 16 October.

U.S. News and World Report. 1981. "A Conversation with William N. Lipscomb." April 20, p. 85 .

\title{
Helpful Hints for Writing Dissertations in Comparative Politics
}

\author{
Peter A. Hall, Harvard University
}

Perhaps fortunately, one is rarely given the opportunity to read fifteen doctoral dissertations in comparative politics within a brief period of time. Having recently served on a committee which presented the opportunity, I can only say that it tends to inspire uncontrollable bouts of reverie about such matters as the state of the discipline, the long-forgotten experience of writing one's own dissertation, the nature of causal arguments, and the inexplicable moments of human frailty that lead one to agree to serve on such a committee in the first place.

One of the subjects to which the mind wanders, however, is more useful than the rest. That is the issue of what makes for a good doctoral dissertation and what pitfalls might be avoided when the final draft is constructed. As I read these dissertations, I was reminded of those newspaper columns about good house- keeping or home repair, with titles like "Hints from Heloise" or "Help Around the House." What advice might Heloise give to the aspiring doctoral student about to put pen to paper? Are there any generic hints about what to aim for and what to avoid in the presentation of the research that might be useful to all who write such a dissertation?

What follows is a list of 'do's' and 'don't's' that occurred to me in the 
course of reading, as they have before in the course of advising, dissertations. The lists are neither definitive nor exhaustive. For that reason, I have deliberately put them in the style of household hints, and perhaps they have no greater import. After all, these are matters on which reasonable people can differ, and this note is not intended to be a treatise in methodology.

It must also be said that the sample of dissertations I read is a very distinguished one indeed. I came away deeply impressed with the dedication, intelligence, and insight of those now entering the field. The committee could easily have awarded several prizes to these dissertations and virtually every one, in its own way, deserved one. What is surprising is that so many first-rate pieces of work still do not entirely escape one pitfall or another. Therefore, I hope that even these brief lists might be of help to those embarking on the writing of such a work.

\section{The 'Do's' of Dissertations in Comparative Politics}

1. Do take some care with the introduction and conclusion to the dissertation, even if you write them last. They are the portions that many readers examine first to identify the overall direction and significance of your work, and a reader's first impressions about the elegance and insight of the text are important.

2. Do identify the basic questions you are addressing in the dissertation relatively early in the introduction and establish why these are interesting questions with reference to a puzzle in the empirical world and/or the contemporary literature on the subject.

3. Do indicate how your study and its questions relate to other studies of and arguments about this general subject.

4. Do include a brief discussion designed to justify your selection of cases with an eye on why your particular cases are good ones in which to test the generalizability of some theoretical propositions.

5. Do take care to ensure that the central concepts used in the study are clear, used consistently and with rela- tively precise empirical reference. If you are in doubt, provide clear definitions. Be careful that your arguments do not turn on distinctions between concepts that might be fuzzy, such as on the difference between 'attitudes' and 'interests,' unless the latter are clearly defined and empirically differentiated.

6. Do give precise page references in the footnotes where you are citing one particular point in a work rather than simply alluding to the thrust of the work as a whole.

7. Do make some effort in each chapter, usually at the beginning or end, to indicate how the material discussed there fits into the study as a whole and, most important, into its argument. You know what you are doing in a way your readers will not, unless you tell them. Therefore, include something like a roadmap here and there in the text to flag where you (and they) are going and where they are at that point in the argument and the presentation of evidence for it.

8. Do attempt to draw some generalizable conclusions about the significance of your study for our understanding of politics itself or of some aspect of the field, whether it be the politics of peasants, the behavior of legislators, the stability of regimes or the like. Almost all dissertations are judged on the overall significance of their findings for broader issues in comparative politics, as well as on what they tell us about a particular case.

9. Do make sure that the theoretical claims you are making are really justified by the empirical account you have presented. For instance, if you are claiming to have developed a theory about how ideas really matter to policy-making, make sure that you have examined the importance of ideas relative to other factors at the critical turning-points in your case-studies. If instead the latter really tell a story about interest groups, realign or scale-back your claims.

\section{The 'Don't's' of Dissertations in Comparative Politics}

1. Don't include everything you have ever learned in graduate school in your introduction. Any literature review should be closely pointed toward the issues that are central to your own study and its treatment of them. Many readers will collapse in hysteria if they have to read yet another review of theories of the state that is only tangentially related to the topic at hand.

2. Don't conclude a 500-page dissertation with a hasty seven-page conclusion. This gives the impression that you have not been able to conclude anything very substantial after four years of work.

3. Don't distort the views of others whose work you are reviewing or disputing into crude stereotypes. On the one hand, the authors whom you are discussing find this quite annoying, as you will too in a few years. On the other hand, such distortion can detract from the real importance of your dissertation by giving the impression that a fine piece of original research is mainly designed to refute a view that no one sophisticated ever really held. Be appreciative, balanced and accurate when you report the views of others, especially when you disagree with them.

4. Don't feel that you have to orient your work primarily toward bowling over some giant theory in the field. If you can do so without undue artifice, fine; but don't forget that it may be even more valuable to extract a positive theory of your own from the research. Many authors have failed to exploit and develop the intrinsic theoretical potential of their own fine work because they felt it necessary to concentrate on attacking someone else's theory.

5. Don't try to include every scrap of empirical information you have gathered from your research in the dissertation itself. If one of the first skills a dissertation writer must learn is to gather information, one of the last is the self-discipline to accept that only a small selection of the most pertinent information should be included in the final manuscript. Wonderful findings discovered after a prodigious amount of research will never receive the attention they deserve if they are buried in an overly-long and unreadably-detailed manuscript. Store the other file cards. 
6. Don't write in the florid style we associate with travelogues or breathless magazine articles. A dissertation need not be written in a dry style, but it should be straightforward, economical and precise in its use of words. Overwriting means using multiple adjectives, sentences, and rhetorical flourishes when fewer would do. It is easy to overwrite when one is highly enthusiastic about a subject and composing an argument about it for the first time. Therefore, it is important to edit.

7. Don't repeat the same material at great length within and between chapters. If you are worried that you have to repeat material for the reader to understand the full significance of the new point you are making, be assured that most readers remember what they have already read, even several chapters before, and a brief reference back will usually suffice to refresh their memory.

8. Don't set up your theoretical claims in such a way that it is hard to imagine how the empirical evidence you set out to collect could ever disprove them. In other words, make sure you have an answer to the question: given the kind of data you collected, if your main theoretical claims happened to be false, how would you have known?

9. Don't fall into the trap of believing that you have to develop a highly elaborate or complex theory for your work to be of significance. All dissertations need some theoretical angle. Some good dissertations develop highly complex theories. Most equally fine ones actually rest on a few fairly simple theoretical claims. If you don't believe me, look at a few books written out of dissertations.

In conclusion, I should say that my only hesitation about compiling these lists derives from the concern that they might make the task of successfully completing a dissertation seem even more daunting than it already is. No one would want that. There are various ways of perceiving the task that help to offset the strain. For instance, I recall one of my colleagues describing his own dissertation as, more or less, simply the longest form he had to fill out in graduate school. There is something in that which should be of comfort to us all.

Without becoming even that modest, however, we can note that a dissertation is often best defined as the bad draft of a good book. There are valid reasons as to why this should be the case, and, precisely for these reasons, no dissertation writer need aim at perfection. The most important accomplishment of all is simply getting the dissertation done. For that reason, in the penultimate stages of my own dissertation, I pinned a note to the wall that read: 'Don't get it right, get it written.' Perhaps with the help of these hints from Heloise one can move some distance toward getting it right before one must finally turn to the even more pressing task of getting it done.

\section{About the Author \\ Peter A. Hall is a professor at Harvard Uni- versity. Hall's research focuses on Compara- tive Politics of Western Europe and Political} Economics.

\title{
Comparative Politics: The Myth of the Eternal Return*
}

\author{
Alfred Diamant, Indiana University
}

In every way, then, such prisoners would recognize as reality nothing but the shadows of these individual artifacts.

\section{Plato, The Republic, \\ "The Allegory of the Cave"}

$\mathbf{W}_{\mathrm{e}}$ are engaged here in an attempt to gain an understanding of the development of a particular branch of the discipline of political science. Erkki Berndtson (1987) has suggested fifteen different ways to do this, either using each of these singly or in combinations of two or more. What I propose to do here, could be termed an effort in the sociology of knowledge, according to Berndtson, plus a dash of an exercise in the "political science of science," that is to say, an examination of the external and in- ternal forces that shape the development of comparative politics. This also involves viewing comparative politics as an organizational system; and even as a "market" where scientists try to add to their academic capital. Finally, it calls for thinking of comparative politics as a "dominance enterprise," a struggle over what is currently acceptable science policy in comparative politics.

What exactly is the institutionalization of comparative research? One is tempted to respond with the sort of categorization that Berndtson has applied to the study of the development of political science as a whole: it is ". . . to study something fuzzy and abstract." The task is further complicated by the fact that whatever institutionalization of comparative politics we can observe in the world largely reflects the high degree of institutionalization of political science in general, and of comparative politics in particular, in the United States.

The developments in comparative politics examined here should be subsumed under the rubric of "differentiation." By using this term I want to suggest that comparative politics was differentiated out of the wider matrix of political science which, in turn, arose as a differentiation from history and law. It seems to me that at least since World War II comparative politics has met the criteria of an "institution," that is to say, there are structures which are governed by a set of rules; there are people interacting within these structures accord- 